\title{
Bactericidal activity of acetone extract of Alpinia galanga on multidrug resistant clinical isolates of Enterococcus faecalis
}

\author{
Aberna R.A. ${ }^{1}$, Prabhakar K. ${ }^{2}$ \\ ${ }^{1}$ Dr. Ramamoorthi Arularasi Aberna, Ph.D., (Medical Microbiology), Lecturer, Department of Microbiology, ${ }^{2}$ Dr. Kesani \\ Prabhakar, Ph.D., Medical Microbiology, Professor, Department of Microbiology; ${ }^{1}$ Rajah Muthiah Dental College and \\ Hospital, ${ }^{2}$ Rajah Muthiah Medical College and Hospital, Annamalai University, Annamalainagar, Tamil Nadu, India.
}

Corresponding Author: Dr. R. Arularasi Aberna, M.Sc., Ph.D., Lecturer in Microbiology, Rajah Muthiah Dental College and Hospital, Annamalai University, Annamalainagar. Tamil Nadu, India. Email: arularasiaberna@gmail.com

\begin{abstract}
Introduction: The objective of the study was to evaluate the inhibitory activity of five traditional Indian medicinal herbs against multidrug resistant clinical isolates of E. faecalis. Methods: Sixty five E. faecalisderived from clinical specimens were tested for their resistance pattern to 7 antibiotics by disc diffusion method. Extracts from 5 medicinal plant parts were obtained and tested for inhibitory activity against multi drug resistant clinical E. faecalisisolates. The minimum bactericidal concentration (MBC) for the active plant extract exhibiting highest activity towards the susceptible isolateswas determined by macro broth dilution method followed by sub culturing on agar plate. Results: All the clinically derived E. faecalis isolates were resistant to two or more antibiotics. Acetone extract of Alpiniagalanga inhibited $67.69 \%$ of E. faecalis and concentration of $<5.0 \mathrm{mg} / \mathrm{ml}$ was found to exert bactericidal activity against multi drug resistant isolates. Conclusion: Acetone extract of A. galanga exhibit bactericidal activity against multi-drug resistant clinical isolates of $E$. faecalis and hence could be potential phytotherapeutic candidate.
\end{abstract}

Keywords: A. galanga, drug resistance, E. faecalis, inhibition, medicinal plants

\section{Introduction}

India is a land of rich heritage for employing medicinal plants in treating illness among its diverse indigenous cultures. Several of these folklore medicines, employing herbs and medicinal plants are validated through scientific research and made accessible to the global population. Therapy through plant products benefits its users by providing generalised immunostimulatory and immunomodulatory effects apart from abating the side effects of antibiotics and monetary expenditure for cure $[1,2]$.

Enterococci are one among the leading nosocomial pathogens commonly associated with urinary tract infections, blood stream infections and catheter related infections. Of more than a dozen species in the genus, Enterococcus faecalis is involved in $70-80 \%$ of clinical infections [3]. Infections by multidrug resistant E. faecalis encompassing even the last line drug of choice are emerging around the globe, accounting for increase in morbidity and mortality rates $[4,5]$.

Manuscript received: $8^{\text {th }}$ May 2018

Reviewed: $18^{\text {th }}$ May 2018

Author Corrected: $24^{\text {th }}$ May 2018

Accepted for Publication: $27^{\text {th }}$ May 2018
E. faecalis is an ideal candidate which deserves a new phytochemical therapeutic agent considering their significance in nosocomial infections and antibiotic resistance. This study unearths the inhibitory activity of five traditional Indian medicinal plants against clinical isolates of E. faecalis. The study is novel and innovative as there are no existing literatures proving the inhibitory potential of acetone extract of Alpinia galanga and its minimalbactericidal concentration (MIC) against drug resistant clinical isolates of $E$. faecalis.

\section{Materials and Methods}

Place of study and type of study: The test-tube lab research study was carried in the Microbiology laboratory of Rajah Muthiah Institute of Health Sciencesto demonstrate the inhibitory activity of traditional medicinal plants on multi-drug resistant E.faecalis obtained from clinical specimens.

Isolation of $\boldsymbol{E}$. Faecalis: The clinical specimens- urine, blood and pus submitted for bacteriological investigation to the Microbiology laboratories at Rajah Muthiah Institute of Health Sciences were employed for 


\section{Original Research Article}

the study. The specimens were inoculated on routine diagnostic culture media and Pfizer's selective enterococcus agar (Hi-Media Laboratories, India). Following aerobic incubation of the inoculated culture plates, colonies morphologically resembling Enterococcus were characterized and identified as $E$. faecalis by standard microbiological and biochemical procedures [6]. The isolates were stored at $-20{ }^{\circ} \mathrm{C}$ in $20 \%$ glycerol Brain Heart Infusion broth (Sisco Research Laboratories Pvt. Ltd., India) until further use.

Detection of antibiotic resistance for clinical $E$. faecalis isolates: E. faecalis obtained from clinical specimens were studied for their antibiotic resistance pattern by disc diffusion test and the results were interpreted according to CLSI, 2012 [7]. The antibiotics (Hi-Media Laboratories, India) tested includes Penicillin (10 units), Ampicillin (10 $\mu \mathrm{g})$, Gentamicin (high content) $(120 \mu \mathrm{g})$, Streptomycin (high content) $(300 \mu \mathrm{g})$, Ciprofloxacin $(5 \mu \mathrm{g})$, Erythromycin $(15 \mu \mathrm{g})$ and Vancomycin $(30 \mu \mathrm{g})$.

Plant extracts employed for study: The plants were chosen based on i) their documented use as antimicrobials in literature and ii) traditional use of these plants among the regional folklore against infections [8]. The plants employed in the study (Table 1) were harvested in Cuddalore district and taxonomically identified.Crude extracts from the plants were extracted with solvents mentioned in Table 1 as per the method described by Eloff [9]. The extracts were stored in the form of dried powder at $-20{ }^{\circ} \mathrm{C}$ until it was used for further biological evaluation.

Determination of inhibitory activity of the plant extracts by disk diffusion test: The plant extracts were tested for their inhibitory activity against the 25 multidrug resistant $E$. faecalis isolates derived from clinical specimens. A single colony from overnight growth on blood agar plates were inoculated in Brain heart infusion broth and incubated at $37^{\circ} \mathrm{C}$ for $4 \mathrm{~h}$.

This bacterial suspension was adjusted to $0.5 \mathrm{Mc}$ Farland Standard and used as inoculum to obtain a lawn culture on Mueller Hinton agar plates (Sisco Research Laboratories Pvt. Ltd., India). Discs (6 $\mathrm{mm}$ in diameter) obtained from Whatmann No.1 filter paper was soaked with the plant extracts reconstituted with $20 \%$ DMSO (to obtain a concentration of $5 \mathrm{mg} / \mathrm{ml}$ ) and placed on the inoculated plates. Suitable controls were included. Following incubation at $37^{\circ} \mathrm{C}$ for overnight period, the plates were evaluated for the presence of zone of inhibition around the discs. The extracts were considered to exhibit anti-E. faecalis activity if a inhibition zone
$>10 \mathrm{~mm}$ was observed was found around the extract impregnated disc.

Determination of the minimum bactericidal concentration (MBC) of $A$. galanga against $E$. faecalis isolates: Macrobroth dilution test was employed to determine the minimum inhibitory concentration (MIC) of A. galangaon susceptible multidrug resistant $\mathrm{E}$. faecalis isolates according to the protocol of CLSI, 2012 [7]. Extract obtained from A. galanga was diluted with Mueller Hinton broth in test tubes to obtain a final concentration of 2.0, 2.5,3.0, 3.5, $4.0,4.5 \mathrm{mg} / \mathrm{ml}$. E. faecalis adjusted to $1.5 \times 10^{8} \mathrm{CFU} / \mathrm{ml}$ was used as inoculum at a quantity of $1 \mathrm{ml}$ on the tubes containing A.galanga extract. Mueller Hinton broth containing E. faecalis suspension alone and A. galanga extract without the inoculum were included as controls. The minimum concentration of A. galanga extract which inhibited the visible growth of $E$. faecalis was considered as MIC value. The MBC of the extract was determined by spot inoculating $10 \mu \mathrm{l}$ of the suspension from macrobroth dilution tubes lacking the growth of $E$. faecalis, on Mueller Hinton agar plates. Following incubation at $37^{\circ} \mathrm{C}$ for overnight period the minimum concentration of the extract that produced no visible colonies was recorded as the MBC value for the strain tested.

\section{Results}

Isolation of $\boldsymbol{E}$. faecalis from clinical specimens: Sixty five isolates of $E$. faecaliswas isolated from urine, pus, blood and ascitic fluid at the isolation rate of $44 \%, 28 \%$, $16 \%$ and $12 \%$ respectively.

Antibiotic resistance pattern of clinical $E$. faecalis isolates: Antimicrobial resistance pattern for E.faecalis isolates showed $72 \%$ of isolates to be high-level gentamicin resistant and $68 \%$ of isolates demonstrated resistance to 2 antibiotics - erythromycin and ciprofloxacin. None of the isolates were found vancomycin resistant (fig. 1).

The clinicalisolates of E. faecalis were found to be resistant to a combination of 2 or more antibiotics (fig. 2 ). Combined resistance to three antibiotics was the frequent observation and was seen among 35\% of isolates. However, none of the isolates were found resistant to all the 7 antibiotics used in the study.

Plant extracts used and their inhibitory activity against $\boldsymbol{E}$. faecalis: Of the 5 plant extracts studied for their inhibitory activity against 65 antibiotic resistant clinical isolates of E. faecalis by disc diffusion test, A.galanga wasfound to inhibit $67.69 \%$ of isolates 
followed by $M$. fragrans which inhibited $47.69 \%$ of isolates (fig.3). Since, A. galanga exhibited inhibitory activity onthe majority of the E.faecalis isolates used in our study, this extract and the strains inhibited by the extract were chosen for further studies.

Minimum bactericidal concentration (MBC) of $A$. Galangal extract for the test isolates: The $44 E$. faecalis isolates which were inhibited by A. galanga extractas determined by disc diffusion test was further studied for the MBC value of A. galanga extract required to inhibit them.A concentration of $3.0 \mathrm{mg} / \mathrm{ml}$ of $A$. galanga extract was found to be the MBC value for a majority of $E$. faecalis isolates (36.3\%). MBC value for more than $50 \%$ of our isolates was $\leq 3.0 \mathrm{mg} / \mathrm{ml}$ (table 2).

\section{Discussion}

In our study, E.faecalis was commonly isolated from urine, followed by pus and blood samples. The predominance of this pathogen in urinary tract infections and pyogenic infections are reported widely $[10,11]$. The $1^{\text {st }}$ line drug of choice for treating enterococcal infections is with a synergistic combination of beta lactam and aminoglycoside antibiotics [12]. In our study, $42 \%$ and $27 \%$ of isolates exhibited resistance to beta lactam class of antibiotics penicillin and ampicillin respectively. Further, highlevel resistance to aminoglycosides- gentamicin and streptomycin was noted with $72 \%$ and $46 \%$ of isolates respectively. With the prevalence of higher resistance rates towards the synergistic antibiotic combinations and the occurrence of multidrug resistance among our clinical isolates, the treatment options for infections demands the role of $2^{\text {nd }}$ and last line drug of choice which are also noted for their adverse effects[10, 13].

The isolation of multidrug resistant $E$. faecalis from clinical specimens in our geographical locality makes the situation imperative to find an alternate treatment option. The phytochemicals of the extracts among the 5 plants selected in the study have proven antibacterial activity against common Gram positive and Gram negativepathogens $[8,14,15]$. In our study, the extracts from the five selected plants exhibited inhibitoryactivity on $13.84 \%-67.69 \%$ of E. faecalis isolates with A.galangademonstrating inhibition on a majority of isolates. A.galanga is widely cultivated medicinal herb

\section{Original Research Article}

in India and the traditional medicinal systems have used the rhizome for diuretic, expectorant, carminative purposes and in treating tubercular glands, bronchitis, kidney and heart diseases [16]. The chief chemical constituent of rhizome is flavonoid which exerts antibacterial activity through inhibition of nucleic acid synthesis, inhibition of cytoplasmic membrane function, inhibition of energy metabolism, inhibition of the attachment and biofilm formation, inhibition of the porin on the cell membrane, alteration of the membrane permeability and attenuation of the pathogenicity [17, $18]$.

The inhibitory activity of M.fragranssucceeds A.galanga in our study, and was active on $47.69 \%$ of $E$. faecalis. Methanol extracts of M.fragrans was earlier reported to have strong antibacterial activity against multi-drug resistant S.typhi [19]. Extracts from $A$. graveolens, $B$. serrate and $H$. indicus inhibited $9 \%$, $41.53 \%$ and $18.46 \%$ of our isolates. Literatures citing the inhibitory activity of these medicinal plants against several Gram positive, Gram negative bacterial pathogens, yeast and fungi are recorded earlier [20 22].

The acetone extract of A.galangaemployed in our study proved to exhibit inhibitory activity on E.faecalis. However previous studies indicate ether, ethyl acetate, aqueous extract and essential oil of A.galangafor significant antibacterial activity against S.aureus and S.pyogenes [23]. In our study, the MBC of acetone extract of A.galanga for the clinical isolates of E.faecalis ranged between $2.0-4.5 \mathrm{mg} / \mathrm{ml}$, and the concentration of $3.0 \mathrm{mg} / \mathrm{ml}$ of the extract inhibited $36.3 \%$ of isolates.

This concentrationwas found to be lesser when compared tothe study of Okonogi et al. wherein $8 \mathrm{mg} / \mathrm{ml}$ was the MBC of essential oil of A.galanga against S.aureusATCC 25923 [24]. In another study involving human pathogens, an active component 1'-acetoxy chavicol acetate from the ethyl acetate extract of A.galanga demonstrated antibacterial activity against P.acne with the MIC and MBC values of 156 and 312 $\mu \mathrm{g} / \mathrm{ml}$ [25]. A study by Warit $e t$ al. showed the extract of A. galanga and its major component S-enantiomer of acetoxy chavicol acetate exhibited anti-tubercular activity on clinical isolates at $2.0 \mu \mathrm{g} / \mathrm{mL}[26]$.

\section{Conclusion}

As an attempt to elude from the repercussion of antibiotic usagefor pathogenswhich exhibit multiple drug resistance, an extensive search is made towards herbal therapy. The study documents the inhibitory activity of acetone extract of A.galanga to be superior compared with other medicinal plants for their anti-E. faecalis activity. Further, bactericidal 


\section{Original Research Article}

activity was demonstrated at concentration of $<5.0 \mathrm{mg} / \mathrm{ml}$ against all the multidrug resistant isolates used in our study. This substantiates the efficacy of A.galanga as an alternative therapeutic option to multiple drug resistant $E$. faecalis.

Table-1: Plant extracts used for the study

\begin{tabular}{|c|c|c|c|}
\hline Plant(scientific name) & Family & Parts used & Solvent for extract preparation \\
\hline Anethumgraveolens & Apiaceae & Fruits & Water \\
\hline Alpinia galanga & Zingiberaceae & Rhizome & Acetone \\
\hline Boswellia serrate & Burseraceae & Gum resin & Methanol \\
\hline Hemidesmus indicus & Asclepiadaceae & Root & Chloroform \\
\hline Myristica fragrans & Myristicaceae & Seeds & Methanol \\
\hline
\end{tabular}

Table-2: MBC of A. galanga extract for $E$. faecalis

\begin{tabular}{|c|c|}
\hline $\begin{array}{c}\text { MBC values of } \boldsymbol{A} \text {. galanga } \\
(\mathbf{m g} / \mathbf{m l})\end{array}$ & $\begin{array}{c}\text { No. of } \boldsymbol{E} \text {. faecalis isolates inhibited by the extract } \\
\text { (Percentage of isolates) }(\mathbf{n}=\mathbf{4 4})\end{array}$ \\
\hline 2.0 & $2(4.5)$ \\
\hline 2.5 & $6(13.6)$ \\
\hline 3.0 & $16(36.3)$ \\
\hline 3.5 & $14(31.8)$ \\
\hline 4.0 & $4(9.1)$ \\
\hline 4.5 & $2(4.5)$ \\
\hline
\end{tabular}

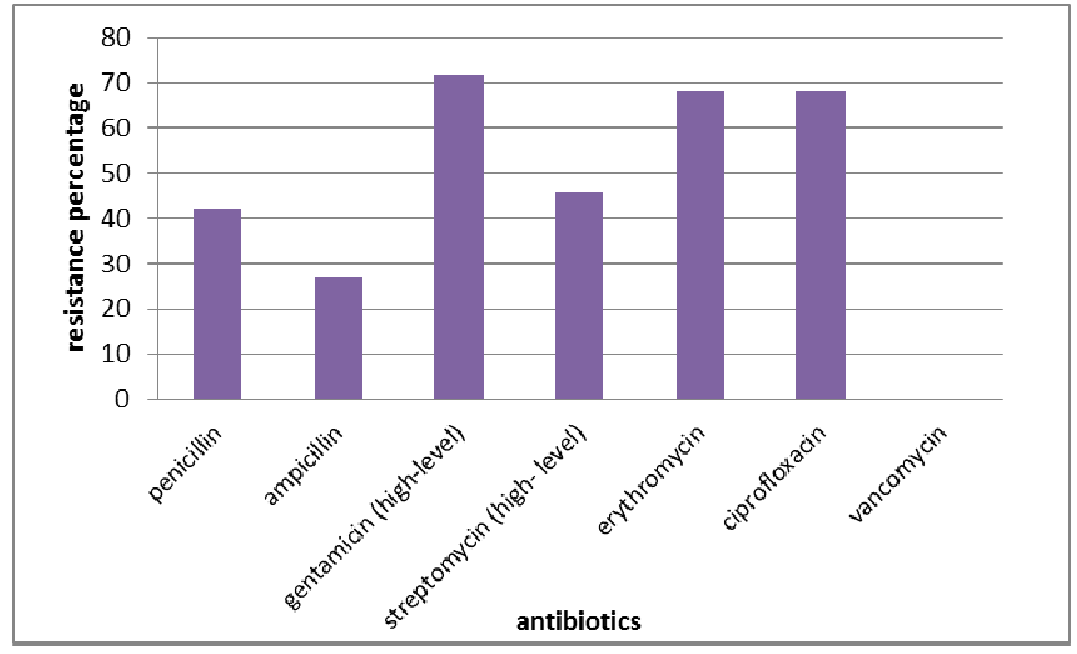

Fig-1: Antibiotic resistance pattern of clinical E. faecalis isolates

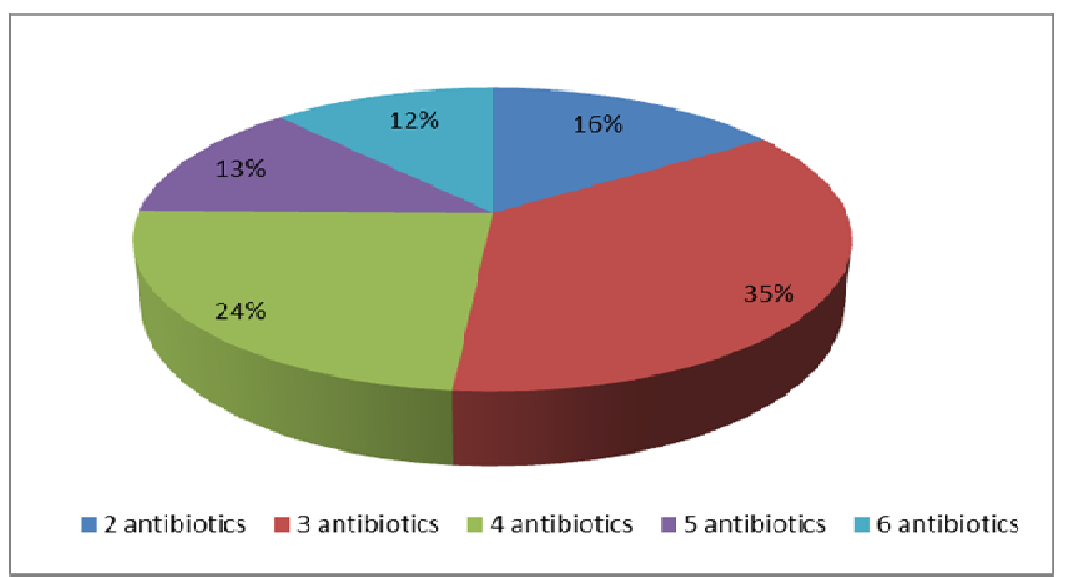

Fig-2:Percentage of $E$. faecalis isolates demonstrating resistance to a combination of 2 or more antibiotics 


\section{Original Research Article}

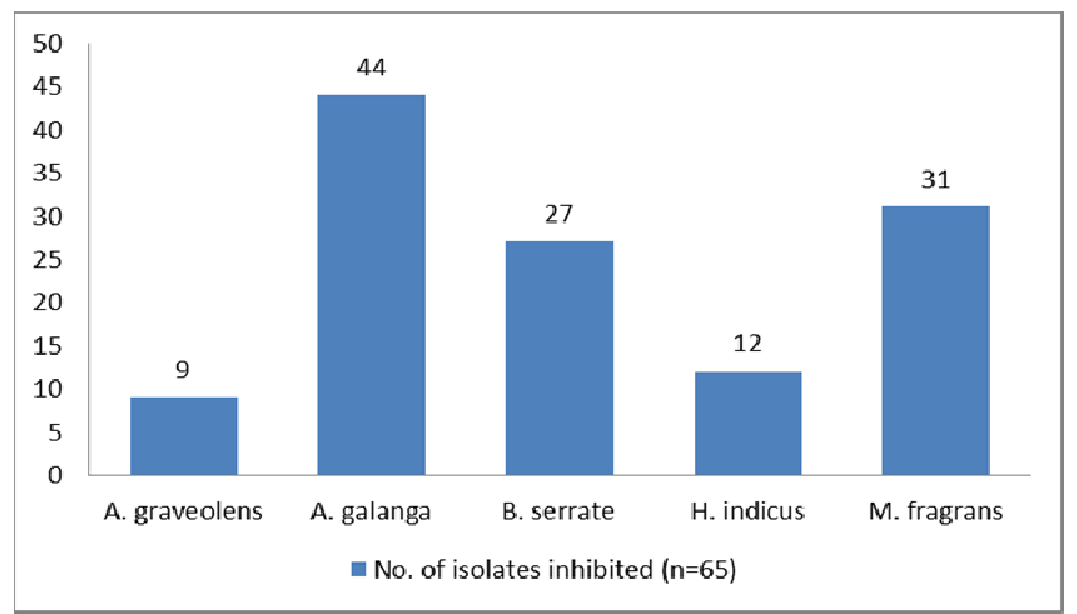

Fig-3: Inhibitory activity of plant extracts on $\boldsymbol{E}$. faecalis isolates

Acknowledgements: The authors wish to acknowledge the technical assistance rendered by Mr. R. Venkatesan and the help for the laboratory work by Mr. Raman, Rajah Muthiah Dental College and Hospital, Annamalai University.

\section{Authors Contributions}

R. Arularasi Aberna and K.Prabhakar contributed to the conception and the design of the experiment.

R. Arularasi Aberna performed the experimental analysis, interpretation and manuscript writing.

K.Prabhakar critically evaluated the paper.

Funding: Nil, Conflict of interest: None initiated

Permission from IRB: Yes

\section{References}

1. Calixto JB. Efficacy, safety, quality control, marketing and regulatory guidelines for herbal medicines (phytotherapeutic agents). Brazilian Journal of medical and Biological research. 2000 Feb;33(2): 179-89.

2. Kumar S, Gupta P, Sharma S, Kumar D. A review on immunostimulatory plants. Journal of Chinese Integrative Medicine.2011Feb;9(2):117-28.doi: 10,3736 / jcim20110201.

3. Fisher K, Phillips C. The ecology, epidemiology and virulence of Enterococcus. Microbiology. 2009 Jun 1; 155 (6):1749-57.

4. Cosgrove SE. The relationship between antimicrobial resistance and patient outcomes: mortality, length of hospital stay, and health care costs. Clinical Infectious Diseases. 2006 Jan 15; 42(Supplement_2):S82-9.doi: 10. $1086 / 499406$

5. Puchter L, Chaberny IF, Schwab F, Vonberg RP, Bange FC, Ebadi E. Economic burden of nosocomial infections caused by vancomycin-resistant enterococci. Antimicrobial Resistance \& Infection Control. 2018 Dec;7(1):1.doi:10.1186/s13756-017-0291z.
6. Facklam RR, Collins MD. Identification of Enterococcus species isolated from human infections by a conventional test scheme. Journal of clinical microbiology. 1989 Apr 1; 27(4):731-4.

7. CLSI. 2012. Methods for dilution antimicrobial susceptibility tests for bacteria that grow aerobically; approved standard, 9th ed. CLSI document M07-A9. CLSI, Wayne, PA.

8. Warrier PK and Nambiar VP. Indian medicinal plants: a compendium of 500 species. Orient Blackswan; 1993.

9. Eloff JN. Which extractant should be used for the screening and isolation of antimicrobial components from plants?. Journal of ethnopharmacology. 1998 Feb $1 ; 60(1): 1-8$.

10. Udo EE, Al-Sweih N, Phillips OA, Chugh TD. Species prevalence and antibacterial resistance of enterococci isolated in Kuwait hospitals. Journal of medical microbiology. 2003 Feb 1; 52(2):163-8.doi:10. 1099/jmm.0.04949-0 


\section{Original Research Article}

11. Jahansepas A, Aghazadeh M, Rezaee MA, Hasani A, Sharifi Y, Aghazadeh T, Mardaneh J. Occurrence of Enterococcus faecalis and Enterococcus faecium in various clinical infections: detection of their drug resistance and virulence determinants. Microbial Drug Resistance. 2018 Jan 1;24(1):76-82.doi:10.1089/ mdr. 2017.0049

12. Sood S, Malhotra M, Das BK, Kapil A. Enterococcal infections \& antimicrobial resistance. Indian Journal of Medical Research.2008 Aug 1;128 (2): 111.

13. Shah L, Mulla S, Patel KG, Rewadiwala S. Prevalence of enterococci with higher resistance level in a tertiary care hospital: a matter of concern. Natl J Med Res. 2012;2(1):25-7.

14. Jirovetz L, Buchbauer G, Shafi MP, Leela NK. Analysis of the essential oils of the leaves, stems, rhizomes and roots of the medicinal plant Alpinia galanga from southern India. ACTA PHARMACEUTICA-ZAGREB-. 2003 Jun;53(2):73-82.

15. Jangid K, Jayakumar ND, Varghese SS. Achievable therapeutic effects of Myristica fragrans (nutmeg) on periodontitis a short review. Int. J. Pharm. Pharm. Sci. 2014; 6(5):591-4.

16. Chudiwal AK, Jain DP, Somani RS. Alpinia galanga Willd.-An overview on phyto-pharmacological properties.

17. Shetty GR, Monisha S. Pharmacology of an endangered medicinal plant Alpinia galanga-a review. Research Journal of Pharmaceutical, Biological and Chemical Sciences. 2015;6(1):499-511.

18. Xie Y, Yang W, Tang F, Chen X, Ren L. Antibacterial activities of flavonoids: structure-activity relationship and mechanism. Current medicinal chemistry. 2015 Jan 1;22(1):132-49.
19. Rani P, Khullar N. Antimicrobial evaluation of some medicinal plants for their anti-enteric potential against multi-drug resistant Salmonella typhi. Phytotherapy Research. 2004 Aug 1;18(8):670-3.

20. Dhiman C, Kumar N,Kothiyal P. Pharmacological actions of Anethum graveolens (Dill). Journal of Pharmacy Research Vol., 2017; 11(5):511-6.

21. Raja AF, Ali F, Khan IA, Shawl AS, Arora DS, Shah BA, Taneja SC. Antistaphylococcal and biofilm inhibitory activities of acetyl-11-keto- $\beta$-boswellic acid from Boswellia serrata. BMC microbiology. 2011 Dec; 11 (1): 54.doi: 10.1186/1471/2180-11-54.

22. Harsha L, Thangavelu L. Screening of Ethanolic Extracts of Medicinal Herbal Drugs against Oral Microbes. Pharmacognosy Journal. 2017; 9(2):201-3. doi: 10.5530/pj.2017.2.33.

23. Al-Snafi AE. Therapeutic properties of medicinal plants: a review of their immunological effects (part 1). Asian Journal of Pharmaceutical Research. 20155(3): 208-16.doi: 10.4103/phrev.phrev_48_17

24. Okonogil S, Prakatthagomol W, Ampasavate C, Klayraung S. Killing kinetics and bactericidal mechanism of action of Alpinia galanga on food borne bacteria. African Journal of Microbiology Research. 2011 Sep 16;5(18):2847-54.doi: 10.5897/AJMR10.396.

25. Niyomkam P, Kaewbumrung S, Kaewnpparat S, Panichayupakaranant P. Antibacterial activity of Thai herbal extracts on acne involved microorganism. Pharmaceutical biology. 2010 Apr 1; 48(4):375-80.doi: 10. 3109/13880200903150443.

26. Warit S, Rukseree K, Prammananan T, Hongmanee P, Billamas P, Jaitrong S, Chaiprasert A, Jaki BU, Pauli GF, Franzblau SG, Palittapongarnpim P. In Vitro Activities of Enantiopure and Racemic 1'-Acetoxychavicol Acetate against Clinical Isolates of Mycobacterium tuberculosis. Scientia pharmaceutica. 2017 Sep 18; 85(3):32.doi: 10.3390/scipharm85030032.

\section{How to cite this article?}

Aberna R.A, Prabhakar K. Bactericidal activity of acetone extract of Alpinia galanga on multidrug resistant clinical isolates of Enterococcus faecalis. Trop J Path Micro 2018;4(2):201-206. doi: 10.17511/jopm.2018.i2.15 